\title{
BREAST AND PROSTATE CANCER
}

\author{
B. K. Sharma and A. Ray \\ Institute of Cytology \& Preventive Oncology (ICMR), Maulana Azad Medical College Campus, \\ Bahadur Shah Zafar Marg, New Delhi-110002.
}

\begin{abstract}
There are interesting similarities between carcinomas of the breast and prostate. Both genetic and exogenous factors are probably important in the development of breast and prostate cancers. Since there is an alarming increasing trend in the incidence of both cancers worldwide including India, high level of apprehension / awareness has been created among the general educated population. Furthermore, both cancers are strongly linked with the expression of the c-erbB-2 oncogene which has been the focus of basic research in the recent past. This gene belongs to the family of growth factor receptors and it has important implication in diagnosis and future treatment modalities.
\end{abstract}

\section{KEY WORDS : Breast cancer, prostate cancer, c-erbB-2 oncoprotein}

At present, the human race witnesses an increasing trend in the incidence of two cancers: breast and prostate cancers, throughout the world including India. Interestingly, both cancers have resemblance in the pathogenesis. Breast cancer is the most frequent cancer in women worldwide with more than half a million new cases being reported every year (1). Although, it is the commonest cancer in women in the developed countries, currently more than $40 \%$ of all breast cancer cases are found in developing countries with the prediction of increase to $50 \%$ by the turn of the century (2). In USA, it is the leading cancer comprising of all cancers in females (3). This percentage varies considerably worldwide in high risk areas, such as North America and northern Europe, breast cancer accounts for one in four female cancers, while in low risk areas such as China and Japan, it accounts for only one in eight to one in sixteen. Similarly, increasing trend in the incidence of clinically diagnosed prostate cancer has been observed. In general, the populations with a high incidence of prostate cancer are those of

\section{Author for correspondence:}

Dr. B.K.Sharma, Deputy Director, at above address. Fax:(91-11) 3233406

e.mail: bhuvnesh10@hotmail.in

bhuvnesh@ndf.vsnl.net.in northern Europe and North America, while the Far East population shows the lowest mortality rates. During the late 1980 's, the incidence rate has rapidly escalated. In 1994, prostate cancer surpassed female breast cancer in the United States (4).

In fact, prostate cancer is the most age related among of all epithelial cancers as the incidence tends to increase in men in their age of early 40's and then contirues to increase logarithmically at about the 8th to 9th power of age throughout the remainder of life. Risk of breast cancer is also strongly age related. Fwo third of cases of breast cancers occur during the postmenopausal period. The age specifir, incidence i.e. the number of cases per year per 100,000 females in each age group displays a progressive increase with aging.

Breast and prostate cancer have several parallels, aside from epidemiological and social factors. Both are mainly adenocarcinomas arising in sexually differentiated organs. Both are strongly influenced by sex-steroid hormones. Dietary fat has received the greatest attention. Several epidemiological studies have revealed countryspecific breast cancer mortality rates with percapitum fat consumption (5). The possible mechanisms linking dietary fat intake to breast 
cancer are not clear, although several hypotheses have been proposed. Some of which have received empirical support from investigations in humans and animals. Fat may increase the risk for breast cancer by interfering with hormonal regulation, which is widely accepted to be involved in the occurrence of breast cancer. The incidence of breast and prostate cancers are closely related in countries where the consumption of fat is the highest. Although, an association between fat consumption and prostate cancer is not fully established, published studies certainly support the existence of such a relationship. One proposed explanation is that dietary fat increases serum sex-hormone levels, a possible risk factor for prostate cancer (6). Both clinical and laboratory studies indicate that oestrogenic steriods play an important role in the aetiology of breast cancer. Oestrogens are important mitogens in-vivo on mammary ducts at the time of puberty, raising the possibilities that local overproduction of oestrogen at early steps of oncogenesis may facilitate development of invasive breast cancer (7). Similarly, cell division in the prostate is under control of androgens. Androgens freely diffuse into prostate epithelium and binds to the androgen receptor. The androgen/ receptor complex translocates to the nucleus for transactivation of androgen responsive genes, including those which control cell division (8). It is interesting to note that many studies $(9,10)$ reported a positive association between serum androgens and breast cancer. Elevated levels of androgens in breast cancer and conversion of androgens into oestrogens in peripheral adipose tissues (aromatization) of women in increasing rate may be responsible for higher risk of breast cancer.

Neuroendocrine cells occur in all areas of the prostate. Neuroendocrine cells in prostatic adenocarcinoma are demonstrable with histochemical and immunohistochemical staining techniques. These cells produce various neuropeptides such as thyroid stimulating hormone (TSH), adrenocorticotropic hormone (ACTH) etc. which may be involved in an autocrine / paracrine pathway of regulation of growth, differentiation, secretion and immune interactions (11). On the other hand, several studies have suggested a striking relationship between breast carcinogenesis and different neuropeptides like melatonin, ACTH, bombesin etc. $(12,13)$. The precise role of these neuropeptides in breast cancer is not clearly elucidated.

The prostate secrete four major proteins primarily to the seminal ejaculate. These four proteins are: prostatic acid phosphatase (PAP), prostate-specific antigen (PSA), prostate-specific protein (PSP-94) and human kallikrein 2 (hK2). At present, the biochemical and pathological mechanisms for the entry of these proteins into the systemic circulation are not well understood. Currently, PSA is the most important diagnostic marker for prostate cancer available to the clinicians. It is relatively reliable, sensitive and specific marker for screening of the high risk population for prostate cancer (14). Recent advances in the management of carcinoma of the prostate have made the use of PSA more important and even indispensable in the practice of uro-oncology. PSA is also secreted by extra-prostatic sources. It is also interesting observation that $30-40 \%$ of female breast tumours produce PSA which is associated with the positive oestrogen receptor (ER) status (15). In addition to this, like human glandular kallikrein (hK2), the breast carcinoma cell-line like T-47D produces PSA when stimulated by glucocorticoids/ mineralocorticoids and other steroid hormones (16). Besides, glucocorticoids up-regulate the PSA gene expression in non-prostatic tissue like breast, it is speculated that PSA may be involved in the regulation of growth factors (17).

High incidence of prostate cancer has been reported in farmers or agricultural workers. In a review of the literature by Blair and Zahm (18) revealed an increased risk of prostate cancer among farmers. The use of pesticides and herbicides appears to be an important area for further research to delineate their carcinogenic potential. One cohort study on Canadian farmers showed a risk assessment of prostate cancer through a dose response relationship between area of the land sprayed with herbicides (19). Environmental factors have long been suspected to play a prominent role in breast cancer aetiology. It has been also suggested that part of the increase in the incidence in breast cancer cases, may be due to unexplained 
environmental factors. It is therefore, most reasonable to speculate a relationship between pesticide exposure and breast cancer (20). Elevated levels of halogenated hydrocarbons in fat samples from women with breast cancer as compared with those who had benign breast disease justify the above speculation (21). Higher levels of DDE in blood of the women with breast cancer as reported by some investigators $(22,23)$ further support the speculation.

It is now well known that prostate cancer is a familial disease. which may possibly be part of the cluster with the family history of other cancers including lymphoma, breast cancer and other solid tumours $(24,25)$. One specific form of hereditary prostate cancer is consistent with an autosomal dominant mode of inheritance in which it has been determined that the putative unknown locus might be responsible for about $9 \%$ of all prostate cancer cases (26). On the other hand, a family history of breast cancer increases the risk. Overall, about 10$15 \%$ of cases may be attributed to family history of breast cancer. There are many changes at the genetic level which are associated with breast cancer. This include the over-expression, rearrangement or amplification of normal cellular genes and proto-oncogenes, mutations that lead to activation of oncogenes or inactivation of suppressor genes and loss of genetic material that presumably represents the loss of suppressor genes as well. In breast cancer, oestrogen controlled, coordinated expression of different genes whose expressions are important for cell proliferation and tissue remodelling such as growth factors, proteases, anti-proteases, transcription factors and membrane receptors. The oestrogen induced proteins are represented: among them, the progesterone receptor and $\mathrm{pS} 2$ are associated with good prognosis while cathepsin D and c-erbB-2 are associated with poor prognosis. Oestrogen stimulates cellular proliferation via the induction of growth regulatory genes.

The progression of the breast cancer is related to a gradual loss of oestrogen requirement for tumour growth. The escape from hormonal control indicates a poor prognosis and may be associated with c-erbB-2 oncogene over-expression (27). High concentration of c-erbB-2 protein is found more frequently in primary breast tumour tissues with a negative receptor status (28). The c-erbB- 2 gene is located on chromosome 17 at q21 and specifiesa transmembrane receptor-like phosphoglycoprotein that is closely related in structure but is still biologically distinct from the epidermal growth factor receptor (EGF-R) (29). The c-erbB-2 (also known as HER-2/ neu) oncogene is the second member of the EGF-R family. The c-erbB-3 gene and c-erbB-4 are the third and fourth member of this family respectively. The c-erbB-2 oncoprotein has intrinsic tyrosine kinase activity. To date, no ligands that directly bind to c-erbB-2 protein have been clearly identified. When c-erbB-2 protein is activated, it can interact with many different cellular proteins which play a role in the signal transduction pathway. It can also interact with the other members of the EGF-R family which include EGF-R, c-erbB- 3 and c-erbB-4 $(30,31)$. The c-erbB-2 gene has been reported to be amplified in most types of adenocarcinomas. The c-erbB-2 oncoprotein has been shown to be expressed through immunohistochemical staining in most subtypes of infiltrating duct carcinoma of the breast (32) while significantly higher proportion of the postmenopausal women with breast carcinoma have been reported to be immunopositive for c-erbB-2 oncoprotein (33). Further, both studies have shown an association of c-erbB-2 oncoprotein positivity with higher histological grading of the tumour. The c-erbB-2 and EGF-R are often overexpressed together in human breast cancer (34) while immunoexpression of cerbB-2 has also been shown significantly associated with poor prognosis (35). In addition, amplification of c-erbB-2 is correlated with the ductal type of invasive carcinomas, oestrogen receptor negative tumours and shortening of disease free survival in the patients with positive axillary lymph nodes (36). Interestingly, expression of c-erbB-2 oncoprotein has also been reported to be associated with large tumour size (37). Further, several studies reported the prognostic significance of c-erbB-2 gene amplification exclusively among node positive patients with breast carcinoma $(38,39)$.

Conflicting results have been reported regarding the $\mathrm{c}-\mathrm{erbB}-2$ in prostate cancer. $\mathrm{A}$ number 
of investigators have studied c-erbB-2 oncoprotein expression by immunohistochemical staining in prostate cancer $(40,41)$. Immunopositivity for C-erbB2 oncoprotein among large number of patients with prostate cancer and its correlation with higher tumour grade and stage, high S-phase and aneuploidy has been reported by several investigators (41-44). Contrary to this, some studies did not observe any significant relationship between c-erbB-2 immunoexpression and tumour stage or grade (45).

The possible prognostic significance of c-erbB$2 /$ neu gene amplification was first published in 1987 by Slamon et al (46). This study on 187 axillary node positive as well as negative patients of breast carcinoma showed c-erbB-2 gene amplification found to be strongly correlated with shortened disease-free survival. Further, c-erbB-2 gene amplification has also been found to be predictive of poorer disease free survival. Thus, the role of $\mathrm{c}$ erbB-2/neu determination to define a high risk subset of node-negative patients has been controversial from the beginning.

\section{Diagnosis and treatment}

Although, there are many ways to diagnose the cancer, however, histological examination is still considered as a reliable tool for definitive diagnosis of carcinoma of the breast. The disease could also be suspected through physical examination, mammography, ultrasonography, cytological screening of needle aspirates as well as through the examination of nipple discharge. The clinical features of breast cancer are not unique which could be easily distinguished from those of benign conditions. The most common physical sign of breast cancer is a mass that can be easily detected in majority of cases by women themselves. A careful collection of the patient's history as well as physical examination are basic fundamental to the evaluation of breast disease, which are indispensable for detection and clinical staging of mammary carcinoma.

The treatment modalities of breast cancer are mainly decided on the basis of clinical stage of the disease. In the earlier stages of the disease, surgeon plays a major role by eradicating the local disease which could be curative. As one of the most popular surgical interventions, total mastectomy, i.e., the removal of the entire mammary gland, is an appropriate operation for prophylaxis against future breast cancer. Further, modified radical mastectomy operation is also removal of the entire breast along with the axillary lymph nodes en bloc but not the pectoralis major muscle. There is no uniform policies on the breast-conserving operations for cancer, which have been done during early stages of the disease. However, the sole objective of all such surgical interventions are complete removal of the primary tumour. It is also being ensured that surgical margins around the tumour should be free of cancer as evident through histopathological findings. Currently, the surgical operations are also being accompanied by an axillary dissection and are followed by therapeutic irradiation of the breast. Oophorectomy is occasionally used; because, usage of synthetic antioestrogen drug-tamoxifen provides identical response without any necessity of such surgical operation. Similarly, adrenalectomy is rarely performed as equivalent treatment effects can be achieved through the usuage of aminoglutethimide. The introduction of aromatase inhibitors has also changed the treatment strategy by eliminating the adrenal substrate for oestrogen production through blockage of its conversion to oestrogen. Chemotherapy offers palliation for patients with advanced breast cancer. This strategy further improves prognosis for some patients with local and regional disease. In India, most commonly used regimen of the treatment of breast cancer is combination of cyclophosphamide, methotrexate and 5-fluorouracil (CMF). In addition, radiation therapy has a pivotal role in the management of a major proportion of women with mammary carcinoma, which is complementary to surgery. Over $15 \%$ of men above 50 years of age develop prostate carcinoma which is associated with latency for years. The incidence of latent carcinoma of the prostate is linked with ageing. However, the patients with localised prostatic carcinoma are mostly asymptomatic, which could be diagnosed during routine rectal examination. Rectal examination still remains the most effective tool in diagnosing early carcinoma of the prostate. Larger 
tumours of the prostate may produce urethral obstruction while in advanced stage of disease, the majority of the patients present with symptoms of bony metastases. Usually, the incidentally diagnosed patients with prostate carcinoma do not exhibit clinically evident disease progression. As such, these patients do not necessarily require any specific therapy other than a 'wait and watch' policy.

Radical prostatectomy is a therapeutic option only when the tumour is confined to the prostate. However, nerve-sparing radical retropubic prostatectomy is a modification in the surgical procedure that can retain potency in many patients as well as decrease the frequency of postoperative incontinence. Further, bilateral orchidectomy either total or subcapsular eliminates the major source of testosterone production. However, in the past years, hypophysectomy and adrenalectomy were used. in the recent past period, blockage of testosterone production could be achieved by using drugs like LHRH agonists (leuprolide and buserelin), inhibitors of adrenal steroids (aminoglutethimide), etc. Similarly, other hormonal agents are also being used such as oestrogens and progestational agents. The nonsteroidal oestrogen diethylstilbestrol (DES) suppresses serum testosterone to castrate levels in a dosage of $3 \mathrm{mg} /$ day. Cytotoxic chemotherapy may be given using a single agent, combination of agents or along with hormonal therapy. In addition, irradiation has been increasingly used for the treatment of prostatic carcinoma. Radiotherapy for metastatic disease often produces dramatic pain relief.

\section{Approaches to targeting c-erbB- I neu overexpressing cancer}

Different strategies have been used to therapeutically target c-erbB-2 overexpressing cancers (47), which inhibit either c-erbB-2 protein function or expression. A recombinant humanized monoclonal antibody directed against c-erbB-2/ neu, trastuzumab (Herceptin, Genetech, San Francisco, CA) has been used in a phase il clinical trial. Several studies have reflected that targeting growth factor receptors using specific antibodies such as trastuzumab can induce regression in some human cancers.
Another possible approach for regulating cerbB-2/ neu is to block its expression by using antisense constructs, either as DNA or oligonucleotides, to directly control the expression of the target gene products without affecting other cellular functions. Several reports have demonstrated that c-erbB-2 antisense oligonucleotides can inhibit c-erbB-2 expression and the cell proliferation rate in vitro (48). Alternatively, the expression of c-erbB-2 can also be blocked by targeting c-erbB-2 / neu promoter by $E 1 A$ and SV 40 large $T$ antigen, as well as the tyrosine kinase activity of the protein using a tyrosine kinase inhibitor, emodin.

\section{Response to tamoxifen:}

There have been several reports that c-erbB-2 overexpressing patients may be resistant to therapy with tamoxifen. However, a number of these studies are based on small number of subjects which can not address this issue in a statistically meaningful way. Tamoxifen only conferred a benefit to the patients who did not overexpress c-erbB-2; no such benefit was seen in the c-erbB-2 overexpressing patients. Nevertheless, the results do not rule out benefit for tamoxifen in ER-positive, c-erbB-2 overexpressing patients. Another study on the efficacy of tamoxifen as front line therapy for metastatic breast cancer revealed response rate to tamoxifen was $57 \%$ in c-erbB-2 negative patients and $47 \%$ in c-erbB- 2 positive patients. However, the difference in response rate was not statistically significant. In light of the relative weakness and conflicting nature of the current data regarding the effects of c-erbB-2 on the efficacy of therapy with tamoxifen, it will be unwise to deny ER-positive, low c-erbB-2 expressing patients may show the possible benefit of this drug. This is particularly true since tamoxifen is one of the best agents for breast cancer therapy, with overall good efficacy and low toxicity.

Hormone dependent cancers represent a paradigm for the role of hormones in cancer development. The expression of thie c-erbB-2 tyrosine kinase receptor oncogene in breast and prostate cancers is regulated by multiple factors 
and hormones, which modulate their growth and differentiation. A growing amount of data is helping to establish the relationship between growth factor receptors family and biochemical response for carcinogenesis; however, much of the present knowledge is inadequate. A number of research activities must be addressed in the field to understand this perplexing pathology.

\section{REFERENCES}

1. Parkins, D.M., Pisani, P. and Fearlay, J. (1993) Estimates of world wide incidence of major cancers in 1995. Int. J. Cancer 54, 594-606.

2. Koroltchouk, V., Stanley, K. and Stjernsward, J. (1990) The control of breast cancer- a world health organization perspective. Cancer 65,2803-2810.

3. National Cancer Institute -Cancer patient survival report No.5(1976) NIH,DHEW Publication No. 77 , 992.

4. American Cancer Society: cancer facts and figures (1994).

5. Hulka, B.S. and Stark, A.T. (1995) Breast cancer: cause and prevention. Lancet 346, 883-887.

6. Giovannucci, E.(1995) Epidemiologic characteristics of prostate cancer. Cancer 75, 1766-1777.

7. Rochefort, H. (1994) Oestrogen, proteases and breast cancer: from cell lines to clinical application. Eur.J.Cancer 30A, 1583-1586.

8. Parker, K.L. and Schimmer, B.P. (1994) The role of nuclear receptors in steriod hormone production. Semin. Cancer Biol. 5, 317-325.

9. Secreto, G., Toniolo, P., Pisani, P., Recchione, C., Cavaller, A., Fariselli, G., Totis, A., Di Pietro, S. and Berrino, F. (1989) Androgens and breast cancer in premenopausal women. Cancer Res. 49, 471-476.

10. Dorgan, J.F., Longcope, C., Stephenson, H.E. Jr., Falk, R. T., Miller, F., Franz, C., Khle, L., Campbell, W.S., Tangrea, J.A. and Schatzkin, A. (1997) Serum sex hormone levels are related to breast cancer risk in postmenopausal women. Enviorn. Health Perspect. 105 (Suppl.3), 583-585.

11. DiSant'Agnese, P.A. and Cockett, A.T.K. (1994) The prostatic endocrine-paracrine neuroendocrine differentiation in prostatic carcinoma: a review and future directions in basic research. J.Urol. 152, 1927-1931.

12. Blask, D.E., Lemus-Wilson, A.M. and Wilson, S.T. (1992) Breast cancer: a model system for studying the neuroendocrine role of pineal melatonin in oncology. Biochem. Soc. Trans. 20, 309311.

13. Sharma, B.K., Ratnakar, N., Murthy, N.S. and Ray, A. (1998) Immunoexpression of ACTH in breast cancer [Abstract]. The Immunologist ( Suppl 1): 624.

14. Cooner, W.H. (1993) Definition of the ideal tumour marker. Urol. Clin. North Am. 20, 575-579.

15. Zarghami, N., Grass, L. and Diamandis, E.P. (1997) Steriod hormone regulation of prostate specificantigen gene expression in breast cancer. Br. J. Cancer 75, 579-588.

16. Hsieh, M.L. ,Charlesworth, M.C., Goodmanson, M., Zhang,S., Seay, T., Klee,G.S., Tindall,D.J., and Young, C.Y.( 1997) Expression of human kallikrein protein ( hK2) in the breast cancer cell line T47-D. Cancer Res. 57, 2651-2656.

17. Diamandis, E.P. and $Y u, H$. (1997) Non prostatic sources of prostate specific antigen. Urol. Clin. North Am. 24, 275-282.

18. Balir, A. and Zahm, S.H. (1991) Cancer among farmers. Occup. Med. 6, 335-354. 
19. Morrison, H., Savitz, D., Sememciw, R., Mulka, B., Mao, Y. and Morrison, D. (1993) Farming and prostate cancer mortality. Am. J. Epidemiol. 137, 270-280.

20. Ray, A. (1997) Pesticide residues and breast cancer. A.M. B.I. Bull. 1, 5 . .

21. Falck, F. Jr., Ricci, A. Jr., Wolff, M.S., Godbold, J. and Deckers, P. (1992) Pesticides and polychlorinated biphenyl residues in human breast lipids and their relation to breast cancer. Arch. Enviorn. Health 47, 143-147.

22. Wolff, M.S., Toniolo, P.G., Lee, E.W., Rivera, M. and Dubin, N. (1993) Blood levels of organochlorine residues and risk of breast cancer. J. Natl. Cancer Inst. 85, 648-652.

23. Dewailly, E., Ayotte, P. and Brisson, J. (1994) Protective effect of breast feeding on breast cancer and body burden of carcinogenic organochlorines. J. Natl. Cancer Inst. 86, 803.

24. Pottern, L.M., Linet, M., Blair, A., Dick, F., Burmeister, L.F. and Gibson, R. (1991) Familial cancers associated with subtypes of leukemia and non-Hodgkin's lymphoma. Leuk. Res. 15, 305-314.

25. Thiessen, E. (1974) Concerning a familial association between breast cancer and both prostatic and uterine malignancies. Cancer 34, 1102-1107.

26. Carter, B.S., Bova, S. and Beaty, T.H. (1993) Hereditary prostate cancer: epidemiologic and clinical features. J. Urol. 150, 797-802.

27. Dati, C., Antoniotti, S., Taverna, D., Perroteau, T. and De Bortolia, M. (1990) Inhibition of c-erbB-2 oncogene expression by estrogen in human breast cancer cells. Oncogene 5, 1001-1006.

28. Takahshi, S., Narimastu, F., Asanuma, H., Okazaki, A., Hirata, K., Mori, M., Chiba, T., Sato, N. and Kikuchi, K. (1995) Immunohistochemical detection of estrogen receptor in invasive human breast cancer: correlation with heat shock proteins, pS2 and oncogene products. Oncology 52, 371-375.

29. Yamamoto, T., Ikawa, S., Akiyama, T., Semba, K., Nomura, N., Miyajima, N., Saito, T. and Toyoshima, K. (1986) Similarity of protein encoded by human c-erbB-2 gene to EGF-receptor. Nature 319, 230 234.

30. Ullrich, A and Schlessinger, J. (1990) Signal transduction by receptors with tyrosine kinase activity. Cell 61, 203-212.

31. Plowman, G.D., Culouscou, J.M. and Whitney, G.S. (1993) Ligand-specific activation of HER4/ p180erbB4, a fourth member of the epidermal growth factor receptor family. Proc. Natl. Acad. Sci. U.S.A. 90, 1746-1750.

32. Sharma, B.K., Ray, A., Kaur, S. and Gupta, S. (1999) Immunohistochemical co-expression of cerbB-2/ Neu oncoprotein, altered tumour suppressor ( p53) protein, EGF-R and EMA in histological subtypes of infiltrating duct carcinoma of the breast. Indian J. Exp. Biol. 37, 223-227.

33. Ratnakar, N., Sharma, B.K., Chaturvedi, K.U., Kaur, S., Naik, S.L.D. and Ray, A. (1998) Immunohistochemical expression of c-erbB-2 oncoprotein and EGF-R in pre- and postmenopausal breast cancer. A.P.M.I.S. 106, 1075-1080.

34. Gullick, W.J. (1990) The role of the epidermal growth factor receptor and the c-erbB-2 protein in breast cancer. Int. J. Cancer 5 ( Suppl), 55-61.

35. Rosen, P.P., Lesser, M.L., Arroyo, C.D., Cranor, M., Borgen, P. and Norton, L. (1995) p53 in nodenegative breast carcinoma: an immunohistochemical study of epidemiologic risk factors, histologic features, and prognosis. J. Clin. Oncol. 13, 821-830.

36. Castiglioni, T., Elsner, B., Curutchet, H.P., Montesinos, M. and Debonis, D. (1995) Immunohistochemical analysis of p53 and c-erbB-2 in breast cancer. Medicina B. Aires 55, 415420. 
37. Wiltschke, C., Kindas-Muegge, J., Steininger, A., Reiner, A., Reiner, G. and Preis, P.N. (1994) Coexpression of HER-2/ neu and p53 is associated with a shorter disease-free survival in nodepositive breast cancer patients. J. Cancer Res. Clin. Oncol. 120, 737-742.

38. Tandon, A.K., Clark, G.M., Chamness, G.C., Ullrich, A. and McGuire, W.L. (1989) HER-2/neu oncogene protein and prognosis in breast cancer. J. Clin. Oncol. 7, 1120-1128.

39. O'Reilly, S.M., Barnes, D.M., Camplejohn, R.S., Bartkova, J., Gregory, W.M. and Richards, M.A. (1991) The relationship between c-erbB-2 expression, S-phase fraction and prognosis in breast cancer. Br. J. Cancer 63, 444-446

40. Natali, P.G., Nicotra, M.R., Bigotti, A., Venturo, I., Slamon, D.J., Fendly, B.M. and Ullrich, A. (1990) Expression of the p185 encoded by HER2 oncogene in normal and transformed human tissues. Int. J. Cancer 45, 457-462

41. Sadasivan, R., Morgan, R., Jennings, S., Austenfeld, M.S., Fabian, C.J., Stephens, R.L., Dobbs, L.J. and Noble, M.J. (1991) Over expression of Her-2/neu may an indicator of poor prognosis in prostate cancer [abstract]. Proc. Am. Assoc. Cancer Res. 32, 166.

42. Natoli, C., Angelucci, D., Tinari, N., Tenaglia, R., Rosini, S., Fioretino, B., Amatetti, C. and lacobelli, S. (1991) Epidermal growth factor receptors, HER-2/neu, and ploidy in prostate cancer [Abstract] Proc. Am. Assoc. Cancer Res. 32, 212.

43. Grob, B.M., Schellhammer, P.F. and Wright, G.L.Jr. (1991) Expression of the c-erbB-2 oncogene in human prostatic carcinomá [abstract]. J. Urol. part 2 145, 294A.

44. Fox, S.B., Persad, R.A., Coleman, N., Day, C.A., Silcocks, P.B. and Collins, C.C. (1994) Prognostic value of c-erbB-2 and epidermal growth factor receptor in stage A1 ( $T 1$ a) prostatic adenocarcinoma $\mathrm{Br}$. J. Urol. $74,214-220$

45. Mellon, K., Thompson, S., Charlton, R.G., Marsh, C., Robinson, M., Lane, D.P., Harris, A.L., Horne, C.H.W. and Neal, D.E. (1992) p53, c-erbB-2 and the epidermal growth factor receptor in the benign and mailgnant prostate. J. Urol. 147, 496-501.

46. Slamon, D.J., Clark, G.M., Wong, S.G., Levin, W.J., Ullrich, A. and McGuire, W.L. (1987) Human breast cancer: correlation of relapse and survival with amplification of the HER-2 / neu oncogene. Science $235,177-182$

47. Baslega, J. and Mendelsohn, J. (1994) Receptor blockade with monoclonal antibodies as anticancer therapy. Pharmcol. Ther. 64, 127-154.

48. Wiechen, K., Zimmer, C. and Dietel, M. (1998) Selection of a high activity c-erbB-2 ribozyme using a fusion gene of c-erbB-2 and enhanced green fluorescent protein. Cancer Gene Ther. 5, 45-51 